\title{
Study of the influence of face pressure on surface settlements by shield tunneling
}

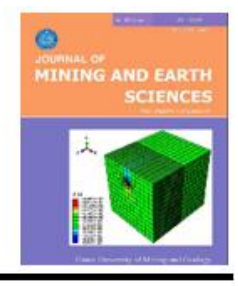

\author{
Thai Ngoc Do 1, ${ }^{*}$, Toan Duc Do ${ }^{2}$ \\ ${ }^{1}$ Faculty of Civil Engineering, Hanoi University of Mining and Geology, Vietnam \\ ${ }^{2}$ Power Engineering Consulting Joint Stock Company 4, Vietnam
}

\section{ARTICLE INFO \\ ABSTRACT}

Article history:

Received $18^{\text {th }}$ Nov 2019

Revised $9^{\text {th }}$ Jan. 2020

Accepted $28^{\text {th }}$ Feb. 2020

Keywords:

Face pressure,

Shield tunneling machines,

Surface settlements,

Tunnel.
In the mechanized excavation of subway tunnels, the shield tunnel boring machine (TBM) has been developed in recent decades for managing the instability of the excavation profile in complicated geotechnical conditions in urban areas. The paper presents a $3 D$ simulation procedure for the detailed description of TBM (via the finite element code Abaqus) and quantifies the influence of TBM face pressure on ground surface settlements. The model is used to calculate ground surface settlements for different values of TBM face pressure. An additional aspect of the investigation is the determination of the critical value of TBM face pressure, which controls face instability in very weak ground. During the advancement of shield tunnel boring machines, the face-stabilizing pressure is one of the most important factors of critical. In tunneling by shield tunnel boring machines, high face pressure often leads to surface upheaval, whereas low face pressure leads to sudden collapse of the face and ultimately settlement of the surface. For the model condition, the maximum value was quantity $250 \mathrm{kPa}$ and the minimum value obtained quantity $150 \mathrm{KPa}$.

Copyright (C) 2020 Hanoi University of Mining and Geology. All rights reserved.

${ }^{*}$ Corresponding author

E-mail: dongocthai@humg.edu.vn

DOI: 10.46326/JMES.2020.61(1).04 


\title{
Tạp chí Khoa học Kỹ thuật Mỏ - Địa chất
}

\section{Nghiên cứu ảnh hưởng của áp lực gương đào đường hầm đến độ lún mặt đất khi thi công đường hầm bằng máy khiên đào}

\author{
Đỗ Ngọc Thái $1{ }^{*}$, Đỗ Đức Toàn ${ }^{2}$ \\ ${ }^{1}$ Khoa Xây dựng, Trường Đại học Mỏ - Địa chất, Việt Nam \\ ${ }^{2}$ Công ty Cổ phần Tư vấn Xây dựng Điện 4, Việt Nam
}

\begin{abstract}
THÔNG TIN BÀI BÁO
Quá trình:

Nhận bài 18/11/2019

Sửa xong 09/01/2020

Chấp nhận đăng 28/02/2020

Tù̀ khóa:

Áp lực bề mặt gương,

Độ lún mặt đất,

Đường hầm,

Máy khiên đào.

\section{TÓM TẮT}

Trong lĩnh vực xây dựng các đường hầm giao thông, máy khiên đào đang rất phát triển trong những năm gần đây để khắc phục các hiện tượng mất ổn định trong quá trình thi công khi gặp các điều kiện địa chất phức tạp trong đô thị. Bài báo sử dưng phương pháp mô hình số 3D bằng phần mềm Abaqus để mô phỏng quá trình thi công đường hầm và dự báo ảnh hưởng của giá trị áp lực gương đào đến độ lún mặt đầt. Mô hình sử dụng để dự báo độ lún mặt đất khi duy trì các giá trị áp lực gương đào khác nhau. Khi thi công đường hầm bằng máy khiên đào việc duy trì áp lực lên gương đào để giữ ổn định bề mặt gương đào đường hầm là một trong số những thông số quan trọng nhất. Trong quá trình thi công, khi giá trị áp lực gương đào quá lớn có thể gây ra các hiên tượng đẩy trồi lên trên mặt đất, khi áp lực gương đào có giá trị nhỏ có thể gây ra các hiện tương trượt lở đột ngột vào trong gưong đào và gây ra sụt lún lên đến mặt đất. Đối với điều kiện bài toán mô phỏng, áp lực bề mặt gương đào hiệu quả có giá trị tối đa là $250 \mathrm{kPa}$ và giá trị tối thiểu là $150 \mathrm{kPa}$.
\end{abstract}

(C) 2020 Trường Đại học Mỏ - Địa chất. Tất cả các quyền được bảo đảm.

\section{Mở đầu}

Quá trình thi công các đường hầm sẽ gây ra những tác động đến khối đất đá xung quanh và các công trình trên mặt đất. Đối với các đường hầm trong đô thị, công tác thi công dưới các tòa nhà cao tầng hay dưới hệ thống kỹ thuật ngầm đô thị luôn tiềm ẩn những rủi ro như gây lún, biến dạng thậm chí gây sập đổ phá hủy các công trình trên mặt đất hay ở vị trí lân cận (Võ Trọng Hùng, Phùng Mạnh

*Tác giả liên hệ

E - mail: dongocthai@humg.edu.vn DOI: 10.46326/JMES.2020.61(1).04
Đắc, 2005; Do Ngoc Thai and Protosenya, 2017). Do đó công tác quy hoạch, thiết kế ban đầu, bao gồm lựa chọn hướng tuyến hay thiết kế kỹ thuật cần thiết đánh giá, dự báo mức độ tác động từ hoạt động thi công đường hầm đến các công trình lân cận, công tác đánh giá dự báo đó mang ý nghĩa rất quan trọng trong quá trình xây dựng đường hầm.

Các phương pháp chính để thi công đường hầm bao gồm phương pháp đào lộ thiên, phương pháp mỏ hay phương pháp đào hầm mới của Áo và phương pháp sử dụng máy khoan hầm. Ngày nay, phương pháp thi công bằng máy khoan hầm đặc biệt là máy khiên đào được áp dụng rộng rãi khi xây dựng các đường hầm tầu điện ngầm trong 
thành phố. Phương pháp thi công bằng máy khiên đào ngoài việc đảm bảo chất lượng công trình, sự ổn định cao cho đường hầm còn giảm thiểu được những ảnh hưởng chấn động, dịch chuyển lún bề mặt đất hay bảo vệ các công trình xung quanh khu vực thi công.

\section{Phưong pháp cân bằng áp lực lên gương đào}

Trong quá trình thi công đường hầm, phía trước gương đào hình thành khối đất đá phá hủy có xu hướng trượt, sụt lở vào trong gương hầm. Độ ổn định gương hầm phụ thuộc rất nhiều yếu tố như đặc tính khối đất mà đường hầm thi công qua, vị trí, kích thước đường hầm, công nghệ thi công. Hiện nay, thi công đường hầm trong điều kiện địa chất yếu chủ yếu sử dụng phương pháp thi công bằng máy khiên đào kiểu kín, phương pháp này cho phép không cần sử dụng các biện pháp giữ ổn định trước khi đào thông thường như hạ mực nước ngầm, khoan phụt vữa hoặc đóng băng. Ngoài ra còn cho phép kiểm soát độ lún bề mặt, hạn chế các rủi ro tại gương đào nhờ vào sự tồn tại liên tục của áp lực chống giữ trên mặt gương đào (Protosenya et al., 2015).

Máy khiên đào là máy đào hầm cơ giới có nhiều chức năng tập trung thống nhất như đào, che chống bảo vệ, lắp đặt vỏ hầm và vận chuyển đất đá. Máy khiên đào thích hợp cho việc thi công đường hầm qua vùng đất đá mềm yếu, phức tạp có nguy cơ mất ổn định cao, đất đá có khả năng sụt lở ngay vào không gian công trình nếu không có kết cấu chống giữ. Phần đầu cắt trang bị hệ thống đĩa cắt có nhiệm vụ phá vỡ khối đất đá, phần kế tiếp có bố trí các kích đẩy cho phép đầu cắt tiến về phía trước, phần đuôi khiên có nhiệm vụ lắp đặt vỏ hầm, vận chuyển đất đá về phía sau và đưa ra ngoài, bơm phụt vữa lấp đầy khoảng trống phía sau vỏ hầm (Vittorio Guglielmetti et al., 2007).

Khoang công tác ở phía sau mâm cắt luôn duy trì áp lực nhằm cân bằng áp lực nước ngầm và áp lực đất đá để giữ ổn định cho gương hầm và giảm những dịch chuyển lún trên mặt đất. Theo nguyên lý chống giữ gương bằng phương pháp cân bằng áp lực gương thì máy khiên đào được chia ra: khiên cân bằng áp lực khí nén; khiên cân bằng áp lực vữa và khiên cân bằng áp lực đất.

- Khiên cân bằng áp lực khí nén: khi thi công qua địa tầng có chứa nước ngầm, để ngăn chặn không cho nước ngầm xâm nhập vào buồng công tác, do đó buồng công tác luôn được duy trì mộtáp lực khí nén. Nhờ áp lực khí nén mà nước ngầm không chỉ bị giữ lại mà còn bị đẩy sâu vào trong đất.

- Khiên cân bằng áp lực vữa: khiên đào áp lực vữa áp dụng phù hợp cho địa tầng có bề mặt gương có thể chống đỡ bằng dung dịch vữa áp lực, thi công trong những địa hình khó khăn như dưới các sông hồ hoặc dưới tầng nước ngầm, đất đào ra được đưa ra ngoài qua ống dẫn, đá cuội, sỏi được nghiền ra và di chuyển ra ngoài qua đường ống. Áp lực nước ngầm, áp lực địa tầng được cân bằng với áp lực dung dịch vữa. Áp lực dung dịch vữa được duy trì thích hợp cho việc tạo lên màng bùn chống đỡ khối đất trước gương. Đĩa cắt phía trước gương cào bóc khối đất ở mặt ngoài màng bùn. Hỗn hợp bùn đất trước gương sau khi được tách bóc được bơm hút đưa lên bề mặt đất để xử lý.

- Khiên cân bằng áp lực đất: đất được đào bởi đầu cắt của khiên sẽ được sử dụng để gia cố gương hầm. Chất tạo bọt được bơm vào trước đầu cắt làm cho đất kết dính lại đảm bảo kiểm soát chính xác áp lực cân bằng gương hầm. Đất sau khi tách bóc ra sẽ theo rãnh dao cắt tiến vào khoang công tác. Khi áp lực trong khoang công tác đủ lớn để chống lại áp lực địa tầng và áp lực nước ngầm thì mặt gương đào sẽ giữ được ổn định mà không bị sụt lở. Yêu cầu cần giữ cho lượng đất trong máng xoắn ốc và lượng đất trong khoang công tác cân bằng với lượng đất đào ra khi tiến vào trong khoang công tác. Đất đào ra được vận chuyển trong máng xoắn ốc ở phía sau khoang công tác theo cửa xả được đưa ra ngoài. Khiên cân bằng áp lực đất thích hợp với các địa tầng đất sét, đất có thành phần dính kết,... đồng thời bảo vệ có hiệu quả sự ổn định bề mặt gương đào, giảm được độ lún bề mặt, trong khi thi công dễ dàng thao tác và có tính an toàn cao. Khi thi công qua các tầng đất cát, sỏi, cần trộn thêm dung dịch vữa, phụ gia,... để cải tiến đặc tính của khối đất sau khi đào ra, như tăng tính lưu động, lấp đầy khoang công tác làm ổn định bề mặt gương.

\section{Dự báo giá trị lún mặt đất}

Phương pháp bán thực nghiệm được các nhà nghiên cứu R.B.Peck, (1969) và Schmidt, (1974) đề xuất bằng cách đo một số điểm tại hiện trường, kết quả thu được là dưới tác động của quá trình thi công đường hầm thì trên mặt đất sẽ hình thành vùng lún (Hình 1), đường cong lún mặt đất thể hiện trên Hình 2. 
Khi thi công đường hầm trong môi trường đất đồng nhất, đẳng hướng thì gây ra độ lún trên bề mặt có giá trị $\left(S_{v}\right)$ đường cong lún bề mặt đất được Peck, (1969) giả định có dạng hàm phân phối chuẩn Gauss, với điểm lún cực đại $S_{\text {v.max }}$ nằm ngay trên trục thằng đứng của đường hầm:

$$
S_{v}=S_{v \cdot \max } \cdot e^{-\left[x^{2} /\left(2 . i^{2}\right)\right]}
$$

Trong đó: $S_{\text {v.max }}$ - Giá trị độ lún lớn nhất theo phương thẳng đứng dọc trục đường hầm, $\mathrm{m} ; \mathrm{x}$ khoảng cách từ trục đường hầm đến điểm khảo sát theo phương nằm ngang, $\mathrm{m} ; i$ - Khoảng cách từ trục đường hầm đến điểm uốn theo phương nằm ngang, $\mathrm{m}$.

Theo O'Reilly and New (1982) giá trị khoảng cách từ tâm đường hầm đến điểm uốn theo phương nằm ngang (i) được xác định theo công thức:

$$
i=\left(K \cdot z_{0}\right)
$$

Trong đó: $K$ - Tham số chiều rộng vùng lún, phụ thuộc vào điều kiện và loại đất mà đường hầm thi công qua, ví dụ đối với cát trong điều kiện nước ngầm ta có $K=0,2 \div 0,3$ và đối với đất sét ta có $K=$ $0,4 \div 0,7 ; z_{0}$ - Chiều sâu bố trí đường hầm, $\mathrm{m}$.

Thể tích vùng lún trên mỗi đơn vị chiều dài đường hầm được xác định theo công thức:

$$
V_{S}=\int_{-\infty}^{\infty} S_{v \cdot \max } \cdot e^{-\left[x^{2} /\left(2 \cdot i^{2}\right)\right]}=\sqrt{2 \pi} \cdot i \cdot S_{v \cdot \max }
$$

Lượng mất thể tích đất $\left(V_{L}\right)$ là tỷ số giữa thể tích của vùng lún và thể tích đào lý thuyết tính cho một đơn vị chiều dài.

$$
\mathrm{V}_{\mathrm{L}}=\left(\mathrm{V}_{\mathrm{S}} / \mathrm{V}_{0}\right) .100 \%
$$

Trong đó: $V_{0}$ - Thể tích đào lý thuyết, $\mathrm{m}^{3}$.

Lượng mất thể tích là do sự khác biệt về thể tích đào đường hầm và thể tích hoàn thành sau khi lắp đặt vỏ chống. Đất xung quanh đường hầm di chuyển để lấp đầy sự mất thể tích này, cường độ di chuyển lấp thể tích cũng gây ra lượng mất thể tích, giá trị mất thể tích còn phụ thuộc vào phương pháp đào, loại đất công trình đào qua và sự thận trọng của đơn vị thi công đường hầm. Một phần của lượng hao hụt thể tích đất xung quanh hầm sẽ phát triển lên đến bề mặt và tạo ra vùng lún. Hay nói cách khác, thể tích vùng lún trên mặt đất tương ứng với lượng mất đất xung quanh đường hầm.

Từ các công thức (1), (2) và (3) độ lún tại điểm bất kỳ trên mặt đất được xác định theo công thức:

$$
S_{v}=\frac{V_{S}}{\sqrt{2 \pi} \cdot K \cdot z_{0}} \cdot e^{-\left[x^{2} /\left(2 K^{2} \cdot z_{0}^{2}\right)\right]}
$$

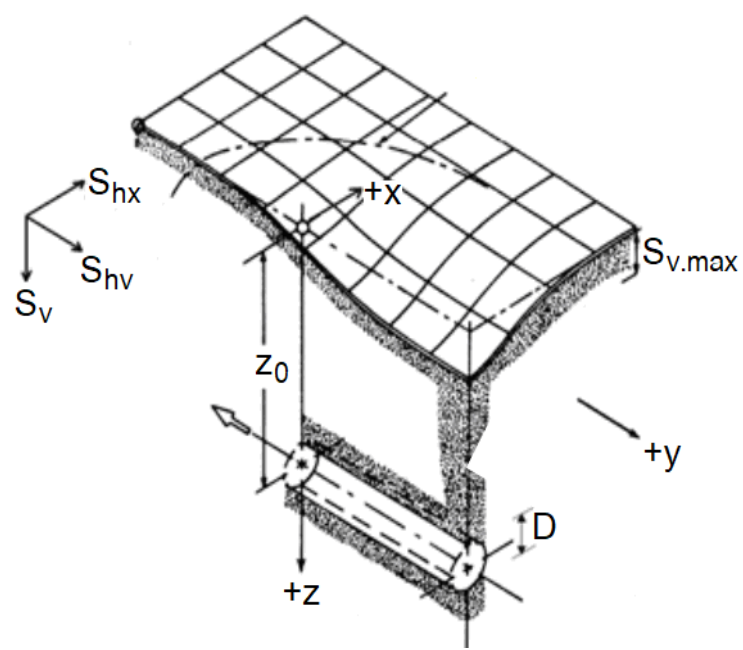

Hình 1. Hình dạng vùng lún trên mặt đất sau khi thi công đường hầm.
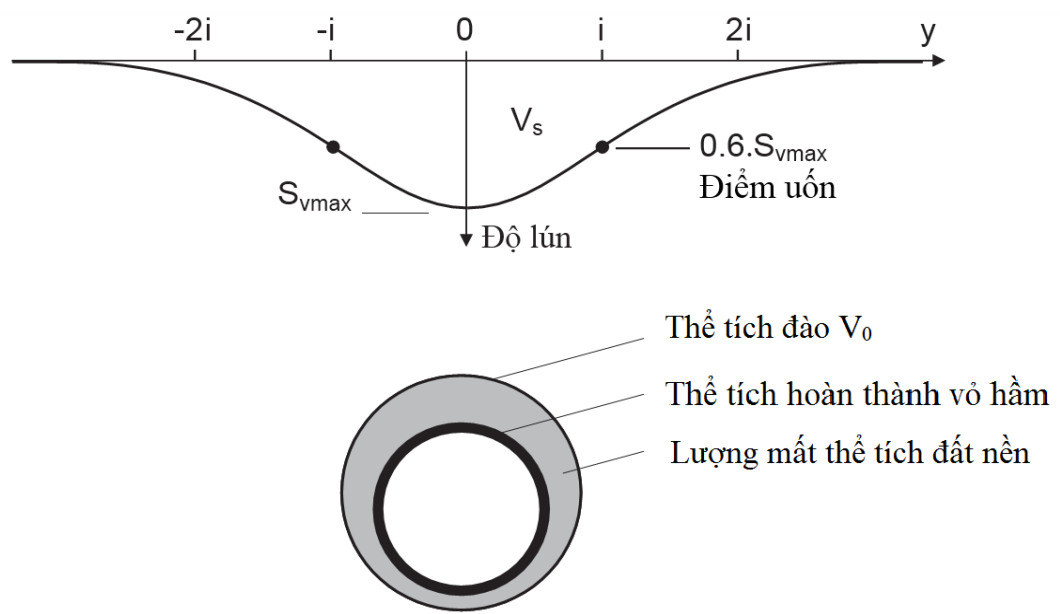

Hình 2. Đường cong lún bề mặt đất và lượng mất thể tích. 
Phương pháp dự báo lún bề mặt khi thi công đường hầm tàu điện ngầm thành phố có thể sử dụng phương pháp giải tích hoặc phương pháp mô hình số. Để dự báo giá trị lún mặt đất gây ra từ công tác thi công một đường hầm cụ thể có thể kết hợp nhiều phương pháp dự báo và được so sánh với kết quả đo đạc, quan trắc thực tế của các công trình có điều kiện xây dựng tương tự. Trong Bảng 1 thể hiện kết quả đo đạc, quan trắc thực tế giá trị lún mặt đất gây ra bởi công tác xây dựng đường hầm.

Theo kết quả đo đạc quan trắc thực tế, giá trị lún mặt đất gây ra bởi công tác xây dựng đường hầm trên Bảng 1 ta thấy, đối với các đường hầm thi công trong điều kiện thành phố thì phương pháp thi công phổ biến là sử dụng máy khiên đào cân bằng áp lực đất và máy khiên đào cân bằng áp lực vữa. Các đường hầm có kích thước lớn (đường kính lớn hơn $9 \mathrm{~m}$ ) thì giá trị lún mặt đất có giá trị lớn hơn $17 \mathrm{~mm}$. Các đường hầm có kích thước nhỏ (đường kính nhỏ hơn $4 \mathrm{~m}$ ) thì giá trị lún mặt đất có giá trị nhỏ từ $5 \div 6 \mathrm{~mm}$. Đường hầm có kích thước trung bình như đường hầm tầu điện ngầm $D$ tại Lyon, Pháp có đường kính 6,27 m và độ sâu thi công 16,4 m; sử dụng khiên cân bằng áp lực vữa trong điều kiện thi công cát sét mịn thì kết quả đo đạc, quan trắc giá trị lún mặt đất là 13,5 mm. Như vậy giá trị lún mặt đất phụ thuộc vào kích thước đường hầm, vị trí thi công đường hầm, điều kiện thi công qua như lớp đất sét, đất mùn hay cát pha,... và phương pháp thi công sử dụng loại máy khiên đào cân bằng áp lực lên gương đào đường hầm.

\section{Xây dựng mô hình số}

Để dự báo độ lún mặt đất khi thi công đường hầm bằng máy khiên đào, trong nghiên cứu này sử dụng phương pháp phần tử hữu hạn thông qua phần mềm chuyên dụng Simulia Abaqus 6.12. Phần mềm cho phép phân tích các quá trình thi công tách bóc đất đá, duy trì áp lực ổn định gương đào, công tác lắp dựng vỏ chống và công tác phụt vữa lấp đầy khoảng trống giữa bề mặt đất đá và vỏ chống, đồng thời đưa ra các kết quả giá trị ứng suất và dịch chuyển khối đất đá gây ra bởi công tác thi công đường hầm.

\subsection{Kích thước mô hình}

Kích thước mô hình có ảnh hưởng đến tốc độ tính toán, độ chính xác của kết quả tính toán, vùng phân tích được lựa chọn có kích thước bằng 7,0 lần đường kính hầm theo phương ngang và phương thẳng đứng sao cho vùng ảnh hưởng tạo ra tại đường biên trong kết quả phân tích có giá trị trong giới hạn cho phép. Chiều cao tính từ đỉnh hầm đến lớp biên phía trên bằng chính độ sâu đặt đường hầm. Kích thước mô hình phân tích (100x100x120).

Bảng 1. Kết quả đo đạc, quan trắc thực tế giá trị lún mặt đất gây ra bởi công tác xây dựng đường hầm (Vittorio Guglielmetti et al., 2007).

\begin{tabular}{|c|l|c|c|c|l|}
\hline TT & \multicolumn{1}{|c|}{ Đường hầm } & $\begin{array}{c}\text { Đường } \\
\text { kính, } \mathrm{m}\end{array}$ & $\begin{array}{c}\text { Chiều sâu bố trí } \\
\text { đường hầm, } \mathrm{m}\end{array}$ & $\begin{array}{c}\text { Giá trị lún } \\
\text { mặt đất, } \mathrm{mm}\end{array}$ & $\begin{array}{l}\text { Kiểu máy khiên đào; đường } \\
\text { hầm thi công trong lớp đất. }\end{array}$ \\
\hline 1 & $\begin{array}{l}\text { Hầm đường sắt tại thành phố } \\
\text { Barcelona, Tây Ban Nha. }\end{array}$ & 11,2 & 30,00 & 5,0 & $\begin{array}{l}\text { Khiên áp lực đất; đất sét và } \\
\text { cát. }\end{array}$ \\
\hline 2 & $\begin{array}{l}\text { Hầm thoát nước ở Sudden } \\
\text { Valley, Mỹ. }\end{array}$ & 14,3 & 9,12 & 43,0 & $\begin{array}{l}\text { Khiên cân bằng áp lực đất; } \\
\text { cát bão hòa nước. }\end{array}$ \\
\hline 3 & $\begin{array}{l}\text { Hầm tầu điện ngầm đường số } \\
\text { 1 ờ Madrid, Tây Ban Nha. }\end{array}$ & 9,38 & 15,50 & 18,0 & $\begin{array}{l}\text { Khiên áp lực đất; cát và đất } \\
\text { sét. }\end{array}$ \\
\hline 4 & $\begin{array}{l}\text { Hầm tầu điện ngầm số 2 ở } \\
\text { Madrid, Tây Ban Nha. }\end{array}$ & 9,38 & 17,00 & 21,2 & $\begin{array}{l}\text { Khiên áp lực đất; đất sét và } \\
\text { cát. }\end{array}$ \\
\hline 5 & $\begin{array}{l}\text { Đường hầm ô tô ở Val-de } \\
\text { Marne, Pháp. }\end{array}$ & 3,35 & 7,75 & 5,3 & $\begin{array}{l}\text { Khiên cân bằng áp lực vữa; } \\
\text { sỏi cát. }\end{array}$ \\
\hline 6 & $\begin{array}{l}\text { Đường hầm tầu điện ngầm số } \\
\text { 2 tại Thượng Hải, Trung quốc. }\end{array}$ & 11,2 & 24,50 & 17,9 & $\begin{array}{l}\text { Khiên cân bằng áp lực vữa; } \\
\text { đất mùn, cát pha. }\end{array}$ \\
\hline 7 & $\begin{array}{l}\text { Đường hầm tầu điện ngâm } \mathrm{D} \\
\text { tại Lyon, Pháp. }\end{array}$ & 6,27 & 16,40 & $\begin{array}{l}\text { Khiên cân bằng áp lực vữa; } \\
\text { cát sét mịn. }\end{array}$ \\
\hline
\end{tabular}


Mô hình mô phỏng có kích thước đường hầm có đường kính $D=7 \mathrm{~m}$, được đào tại vị trí độ sâu $Z_{0}=20 \mathrm{~m}$. Lắp dựng vỏ chống bê tông đúc sằn có chiều dày $d=0,35 \mathrm{~m}$, mô đun đàn hồi $E=30 \mathrm{GPa}$, hệ số Poisson $=0,2$ và sử dụng mô hình vật liệu vỏ chống bê tông đúc sẵn là đàn hồi tuyến tính.

Mô hình vật liệu cho các lớp đất được sử dụng mô hình Mohr - Coulomb. Các tham số cơ lý chính của các lớp đất đá được giả định có các tham số như trong Bảng 2.

\section{2. Điều kiện biên}

Biên trái và biên phải của mô hình chọn loại cố định có ứng suất tiếp và chuyển vị ngang tại biên bằng không; ứng suất pháp và chuyển vị thẳng đứng để tự do. Biên đáy của mô hình có chuyển vị ngang, thẳng đứng bằng 0 ; ứng suất tiếp, pháp tuyến để tự do. Biên phía bề mặt để tự do cho phép chuyển vị thẳng đứng và chuyển vị ngang như trên Hình 3 và Hình 4.

Bảng 2. Đặc tính cơ lý các lớp đất.

\begin{tabular}{|c|c|c|c|c|c|c|c|}
\hline TT & Loại đất & $\begin{array}{c}\text { Chiều dày lớp, } \\
H(\mathrm{~m})\end{array}$ & $\begin{array}{c}\text { Khối lượng thể } \\
\text { tích, } \gamma(\mathrm{kN} / \mathrm{m} 3)\end{array}$ & $\begin{array}{c}\text { Mô đun đàn } \\
\text { hồi, } E(\mathrm{MPa})\end{array}$ & $\begin{array}{c}\text { Hệ số } \\
\text { Poisson, }(v)\end{array}$ & $\begin{array}{c}\text { Góc ma sát } \\
\text { trong, } \varphi(0)\end{array}$ & $\begin{array}{c}\text { Lực dính } \\
\text { kết, } c(\mathrm{kPa})\end{array}$ \\
\hline 1 & Sét mềm & 5 & 19,0 & 8 & 0,35 & $8^{0}$ & 12 \\
\hline 2 & Cát & 7 & 19,2 & 15 & 0,35 & $10^{0}$ & 15 \\
\hline 3 & Sét & 21 & 20,0 & 30 & 0,32 & $25^{0}$ & 22 \\
\hline 4 & Đá & 67 & 22,0 & 100 & 0,25 & $32^{0}$ & 30 \\
\hline
\end{tabular}

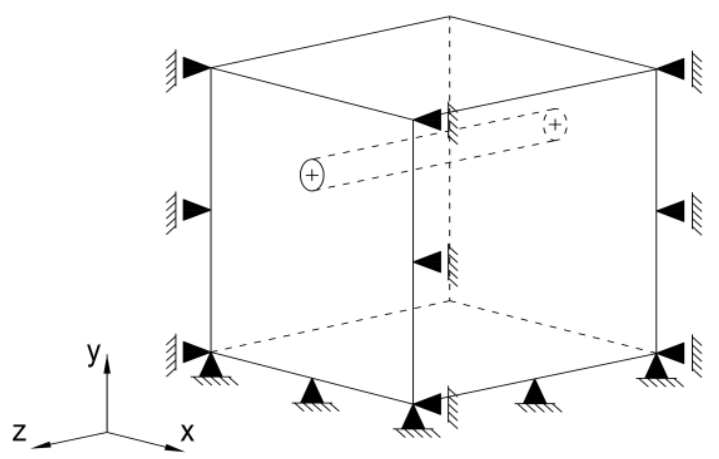

$$
\begin{aligned}
& \begin{array}{l}
u_{y}-\text { tự do } \\
u_{x}=0
\end{array} \mid \tau=0 \\
& \begin{array}{ll}
u_{x}=0 & \bar{\sigma}-\text { tự do }
\end{array} \\
& \text { At } \begin{aligned}
u_{y}=0 \\
u_{x}=0 \\
u_{z}=0
\end{aligned} \quad \bar{\sigma}-\text { tự do }
\end{aligned}
$$

Hình 3. Điều kiện biên bài toán.

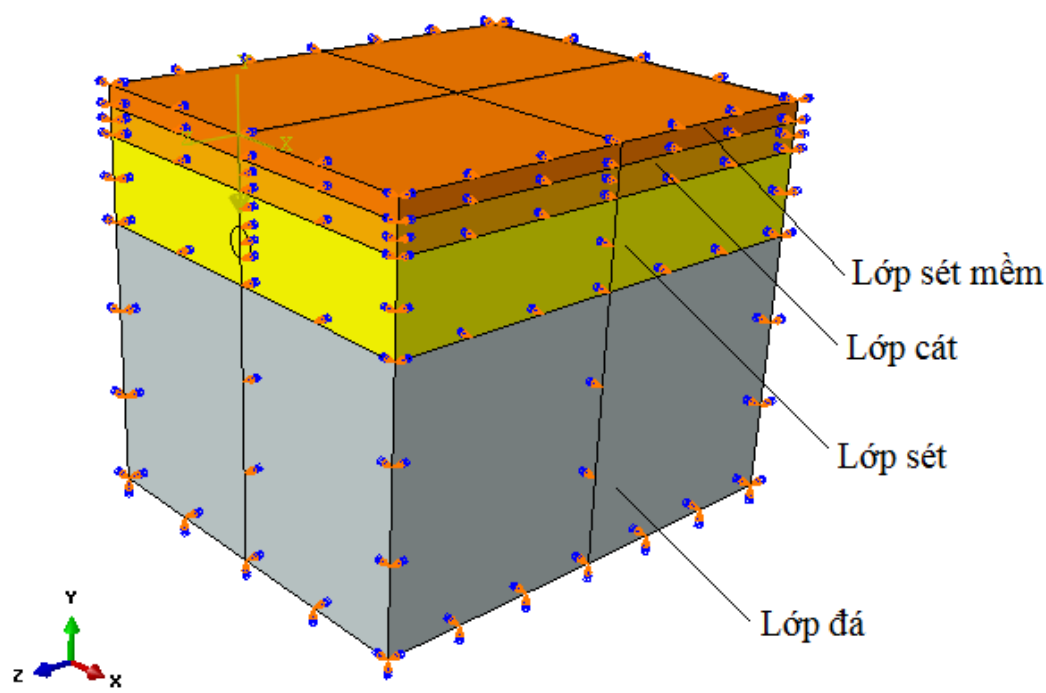

Hình 4. Vị trí các lớp đất đá. 


\section{3. Áp lực lên gương đào}

Trong quá trình thi công đường hầm qua đất yếu, phía trước gương đào hình thành khối đất đá phá hủy có xu hướng trượt, sụt lở vào trong gương đào (Võ Trọng Hùng, Phùng Mạnh Đắc, 2005; Do Ngoc Thai and Protosenya, 2017). Duy trì áp lực lên gương đào có tác dụng nhằm cân bằng áp lực gương giữ ổn định gương đào, kiểm soát, giảm thiểu độ dịch chuyển khối đất đá, lún bề mặt đất. Giá trị áp lực cân bằng gương được xác định phụ thuộc vào đường kính, chiều sâu bố trí đường hầm và các giá đặc tính cơ lý khối đất đá xung quanh. Ở mô hình này để phân tích ảnh hưởng của giá trị áp lực gương đào đến độ lún mặt đất, sử dụng áp lực lên gương đào có giá trị trung bình thay đổi $F_{g}=$ $50 \div 250$ kPa như trên Hình 5 . Áp lực áp lực gương phân bố tuyến tính tăng theo độ sâu, trường hợp duy trì áp lực gương $F_{g}=50 \mathrm{kPa}$ là giá trị áp lực gương trung bình tại trục đường hầm bằng 50 $\mathrm{kPa}$, giá trị áp lực gương tăng tuyến tính theo độ sâu từ đỉnh hầm đến đáy hầm (đường kính $D=7$ $\mathrm{m}$ ) với giá trí biến đổi $12 \mathrm{kPa} / \mathrm{m}$.

\subsection{Các giai đoạn mô phỏng tính toán thi công đưò̀ng hầm}

Các giai đoạn mô phỏng, tính toán công tác thi công đoạn hầm bao gồm:

Giai đoạn 1: xây dựng điều kiện biên, trường ứng suất ban đầu;

Giai đoạn 2: tách bóc đất đá, duy trì áp lực lên gương đào;

Giai đoạn 3: lắp đặt vỏ chống cho đường hầm, duy trì áp lực phụt vữa phía sau vỏ chống.

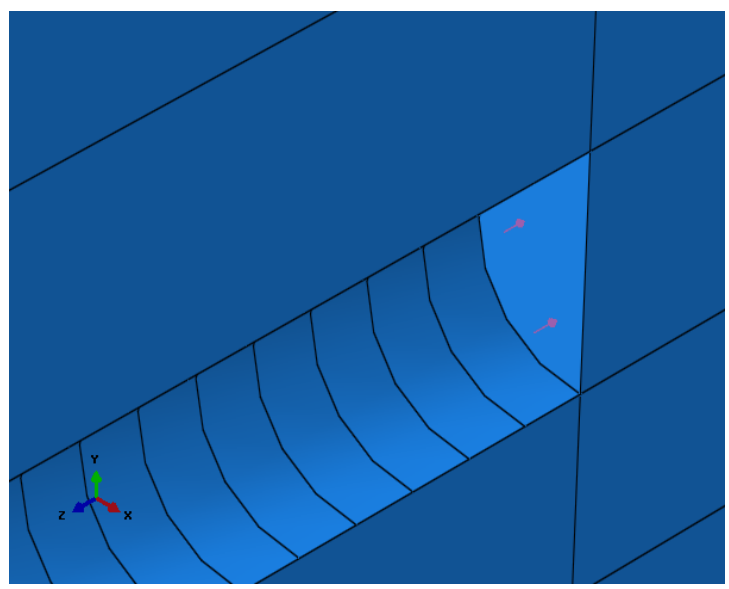

\subsection{Kết quả tính toán}

Kết quả mô phỏng lún mặt đất gây ra bởi công tác thi công đường hầm với các giá trị áp lực gương hầm khác nhau được thể hiện trên Hình 6, Kết quả cho thấy mối tương quan giữa áp lực gương hầm và độ lún mặt đất: khi sử dụng giá trị áp lực gương hầm càng nhỏ thì giá trị độ lún mặt đất càng lớn.

Để đánh giá sự phụ thuộc của giá trị áp lực gương hầm đến độ lún mặt đất, nghiên cứu này thay đổi giá trị áp lực lên gương đào $F_{g}=50 \div 250$ $\mathrm{kPa}$, kết quả thu được giá trị lún mặt đất dọc trục đường hầm thể hiện trong Hình 7.

Từ kết quả phân tích mô hình số thể hiện trên Hình 7 cho thấy giá trị áp lực duy trì lên gương đào có ảnh hưởng đến giá trị lún mặt đất. Khi giá trị áp lực duy trì lên gương đào càng giảm thì giá trị lún mặt đất tăng. Với giá trị áp lực lên gương đào $F_{g}=$ $50 \mathrm{kPa}$ giá trị lún mặt đất là $42 \mathrm{~mm}$ lớn gấp 5 lần giá trị lún mặt đất đối với trường hợp áp dụng giá trị áp lực lên gương đào $F_{g}=250 \mathrm{kPa}$ có giá trị lún mặt đất là $9 \mathrm{~mm}$.

Đối với trường hợp $F_{g}=50 \mathrm{kPa}$ thì tác động từ công tác thi công đường hầm gây ra lún mặt đất có giá trị lớn nhất là $41 \div 42 \mathrm{~mm}$ và ở vị trí gương đào có giá trị lún trên bề mặt đất là $14 \div 15 \mathrm{~mm}$. Giá trị kết quả phân tích cho thấy, giá trị lún trên bề mặt đất ở vị trí gương đào có giá trị bằng $(0,34 \div 0,35)$ lần giá trị lún bề mặt lớn nhất gây ra bởi công tác thi công đường hầm $S_{v \text {-guong }}=(0,34 \div 0,35) S_{v \text {-max. }}$. Vùng ảnh hưởng lún mặt đất phía trước gương đạt tới $30 \div 35$ m, giá trị lún mặt đất đạt giá trị lớn nhất phía sau gương $50 \mathrm{~m}$.

Hình 5. Duy áp lực lên bề mặt gương đào đường hầm. 

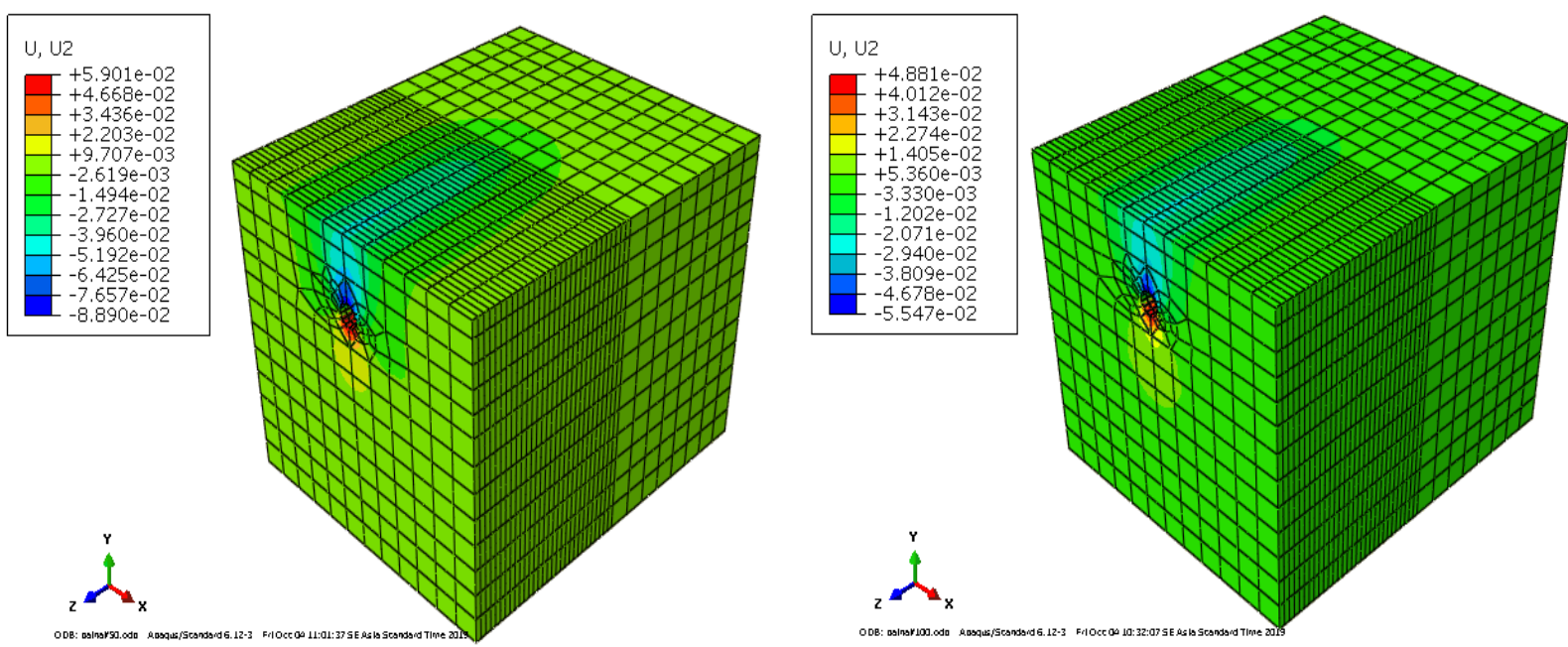

(a)

(b)
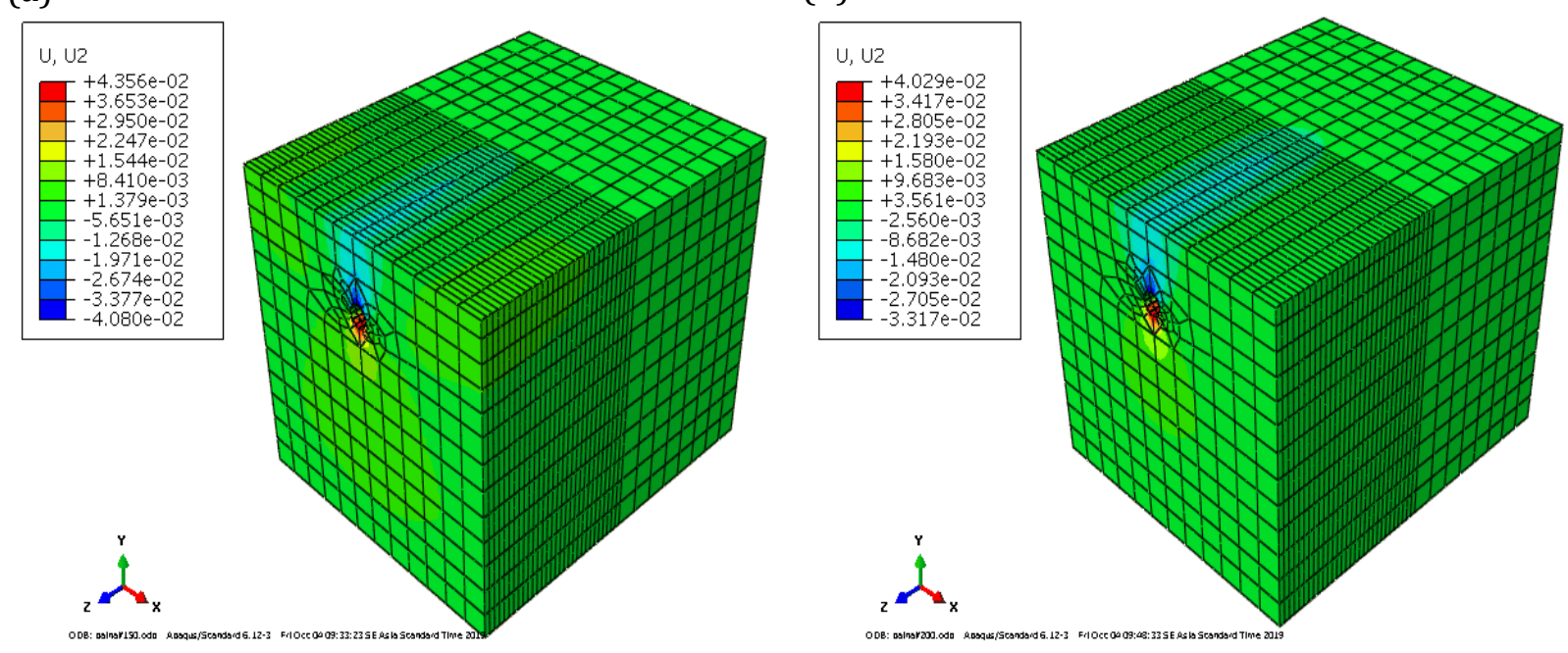

(c)

(d)

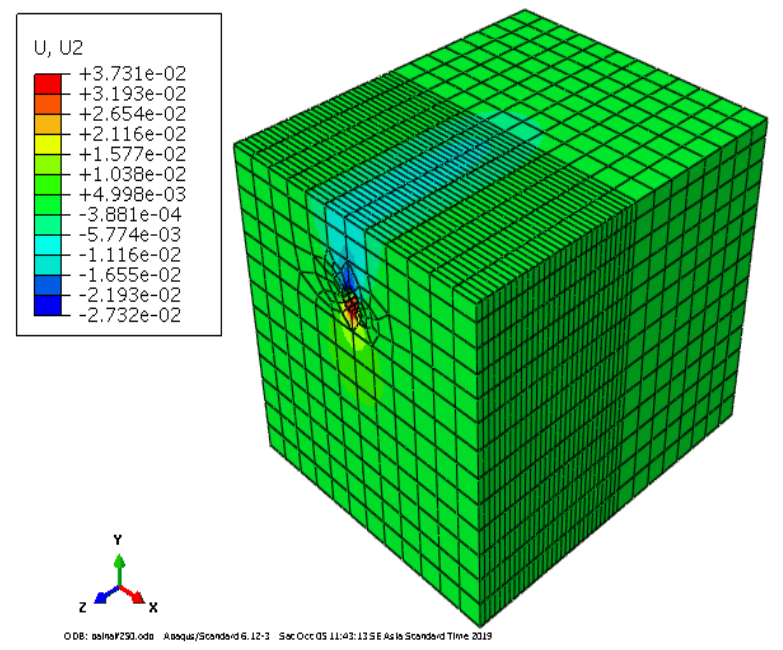

Hình 6. Kết quả mô phỏng giá trị lún mặt đất khi thay đổi giá trị áp lực gương hầm:

(a) - Giá trị áp lưc lên gương $F_{g}=50 \mathrm{kPa}$;

(b) - Giá trị áp lực lên gương $F_{g}=100 \mathrm{kPa}$;

(c) - Giá trị áp lực lên gương $F_{g}=150 \mathrm{kPa}$;

(d) - Giá trị áp lực lên gưong $F_{g}=200 \mathrm{kPa}$;

(e) - Giá trị áp lực lên gương $F_{g}=250 \mathrm{kPa}$.

(e) 


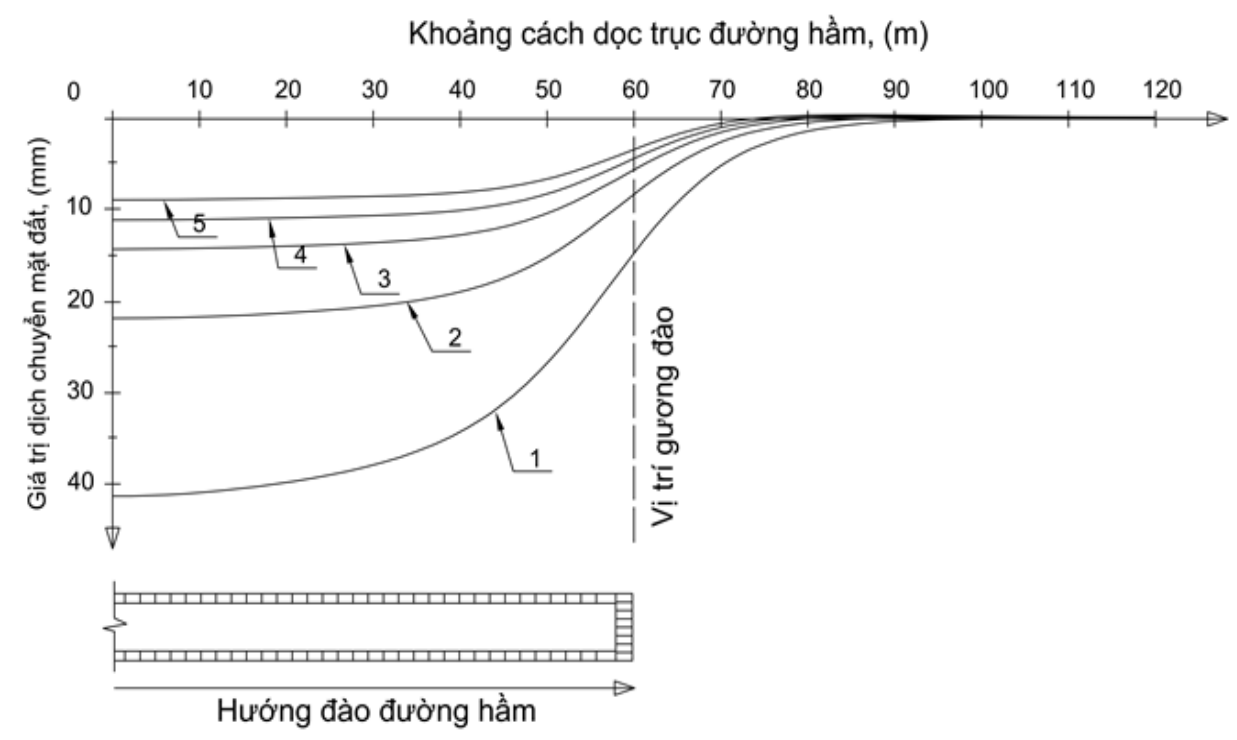

$1-\mathrm{Fg}=50 \mathrm{kPa} ; 2-\mathrm{Fg}=100 \mathrm{kPa} ; 3-\mathrm{Fg}=150 \mathrm{kPa} ; 4-\mathrm{Fg}=200 \mathrm{kPa} ; 5-\mathrm{Fg}=250 \mathrm{kPa}$.

Hình 7. Lún mặt đất dọc trục đường hầm khi sử dụng các giá trị áp lực lên gương đào khác nhau.

Đối với trường hợp $F_{g}=250 \mathrm{kPa}$ thì tác động từ công tác thi công đường hầm gây ra lún mặt đất có giá trị lớn nhất là $8 \div 9 \mathrm{~mm}$ và ở vị trí gương đào giá trị lún trên bề mặt đất là $3 \div 4 \mathrm{~mm}$. Giá trị kết quả phân tích cho thấy, giá trị lún trên bề mặt đất ở vị trí gương đào có giá trị bằng $(0,37 \div 0,44)$ lần giá trị lún bề mặt lớn nhất gây ra bởi công tác thi công đường hầm $S_{v \text {-guoong }}=(0,37 \div 0,44) S_{v-\max }$. Vùng ảnh hướng lún mặt đất phía trước gương đạt tới $15 \div 20 \mathrm{~m}$, giá trị lún mặt đất đạt giá trị lớn nhất tại vị trí phía sau gương $30 \mathrm{~m}$. Tuy nhiên vị trí $20 \mathrm{~m}$ phía trước gương giá trị lún bề mặt có giá trị dương "+", tức là xuất hiện hiện tượng đẩy trồi đất đá, vữa áp lực lên bề mặt đất.

Giá trị dịch chuyển trên mặt cắt ngang được thể hiện trên Hình 8.

Trên hình 8, thể hiện giá trị lún mặt đất lớn nhất trên mặt cắt ngang khi sử dụng các giá trị áp lực lên gương khác nhau. Từ kết quả phân tích mô hình số cho thấy giá trị áp lực duy trì lên gương đào có ảnh hưởng đến giá trị lún mặt đất. Khi giá trị áp lực duy trì lên gương đào càng giảm thì giá trị dịch chuyển lún mặt đất tăng.

\section{Kết luận}

Từ kết quả phân tích mô hình số nhận thấy, đối với đường hầm bố trí nằm gần mặt đất, trong điều kiện địa chất yếu khi thi công dẫn đến hiện tượng lún mặt đất.
Giá trị lún lớn nhất $S_{v-\max }$ xuất hiện phía sau gương đào, cách gương đào $30 \div 50 \mathrm{~m}$. Ở vị trí gương đào giá trị lún trên bề mặt đất đạt $(0,34 \div 0,44) S_{v-\max }$.

Giá trị áp lực duy trì lên gương đào có ảnh hưởng đến giá trị lún mặt đất. Khi giá trị áp lực gương đào quá lớn có thể gây ra các hiện tượng đẩy trồi lên trên mặt đất, khi áp lực gương đào có giá trị nhỏ có thể gây ra các hiện tượng trượt lở đột ngột vào trong gương đào và gây ra sụt lún lên đến bề mặt đất.

Dựa vào các kết quả mô hình số trên và các kết quả quan trắc đo đạc thực tế từ các công trình cùng điều kiện xây dựng, đối với bài toán trên để đảm bảo an toàn trong thi công, giảm giá trị lún mặt đất và không để xảy ra hiện tượng đẩy trồi đất hoặc vữa áp lực lên mặt đất ta lựa chọn giá trị áp lực duy trì lên gương đào là: $150 \mathrm{kPa} \leq F_{g} \leq 250$ $\mathrm{kPa}$.

\section{Tài liệu tham khảo}

Abaqus Inc. Abaqus User's Manual. Version 6.12. Simulia. (2012), 773p.

Do Ngoc Thai and Protosenya, A. G., (2017). The effect of tunnel face support pressure on ground surface settlement in urban areas due to shield tunnelling. Geo - Spatial Technologies and Earth resources (ISM - 2017), 415-420. 
O’Reilly, M. P. and New, B. M., (1982). Settlements above tunnels in the UK - their magnitude and prediction. Tunnelling 82, 173-181.

Peck, R.B. (1969). Deep excavations and tunnelling in soft ground. In: Proc. 7th ICSMFE, State-of-the-art Volume, Mexico City. Mexico: Sociedad Mexicana de Mecánica de Suelos, 225290.

Protosenya, A. G. , Belyakov, N. A. , Do Ngoc Thai, (2015). The development of prediction method of earth pressure balance and earth surface settlement during tunneling with mechanized tunnel boring machines. Proceedings of the mining institute 211, 53-63.
Schmidt, B., (1974). Prediction of Settlements Due To Tunnelling in Soil: Three Case Histories, Proceedings. Rapid Excavation and Tunnelling Conference 2, 1179-1199..

Vittorio Guglielmetti, (2007). Mechanized Tunneling in Urban Areas: Design methodology and construction control / Vittorio Guglielmetti, Piergiorgio Grasso, Shulin Xu; Taylor\&Francis e-Library. 2007, 504p.

Võ Trọng Hùng, Phùng Mạnh Đắc, (2005). Cơ học đá ứng dụng trong xây dựng công trình ngầm và khai thác mỏ. Nhà xuất bản Khoa học kỹ thuật, 463tr. 